\title{
CONTRIBUTIONS OF QUALITATIVE RESEARCH TO EVIDENCE-BASED PRACTICE IN NURSING
}

Rita L. Ailinger ${ }^{1}$

Ailinger RL. Contributions of qualitative research to evidence-based practice in nursing. Rev Latino-am Enfermagem 2003 maio-junho; 11(3):275-9.

Aim. This article aims to identify the contributions of qualitative research to evidence-based practice in nursing. Background. Qualitative research dates back to the 1920s and 1930s, when anthropologists and sociologists used qualitative research methods to study human phenomena in naturalistic settings and from a holistic viewpoint. Afterwards, other subject matters, including nursing, adopted qualitative methods to answer their research questions. The restructuring of health care over the past decade has brought about increased accountability in nursing research. One method for increasing this accountability is evidence-based practice. Method. The method used was a search in the Cumulative Index to Nursing and Allied Health Literature database from 1999-present. The search resulted in 61 citations for evidence-based practice in nursing research; however, only 5 citations focused on evidence-based practice and qualitative research. Findings. The authors' findings revealed six contributions of qualitative research to evidence-based practice: generation of hypotheses; development and validation of instruments; provision of context for evaluation; development of nursing interventions; development of new research questions; and application of Qualitative Outcome Analysis. Conclusion. Qualitative research makes important contributions to the quality of evidence-based practice.

DESCRIPTORS: qualitative research, evidence-based practice, nursing research

\section{CONTRIBUIÇÕES DA PESQUISA QUALITATIVA PARA A PRÁTICA DE ENFERMAGEM BASEADA EM EVIDENCIAS}

Objetivo. Este artigo objetiva identificar as contribuições da pesquisa qualitativa para a prática de enfermagem baseada em evidências. Histórico. A pesquisa qualitativa foi estimulada especialmente a partir dos anos 20 e 30 do século 20 , quando antropólogos e sociológicos passaram a usar métodos qualitativos para estudar o fenômeno humano em ambientes naturais e a partir de ponto de vista holístico. Posteriormente, outras ciências, inclusive a enfermagem, adotaram métodos qualitativos para responder às suas perguntas de pesquisa. A reestruturação da atenção à saúde na última década resultou em uma maior confiabilidade atribuída à pesquisa em enfermagem. A prática baseada em evidências favoreceu este processo. Método. $O$ método utilizado foi a pesquisa no banco de dados Cumulative Index to Nursing and Allied Health Literature de 1999 até o presente. A pesquisa resultou em 61 citações da prática baseada em evidências relacionada à pesquisa em Enfermagem. Todavia, apenas 5 delas focava a prática baseada em evidências e a pesquisa qualitativa. Achados. Os achados revelarem seis contribuições da pesquisa qualitativa para a prática baseada em evidências: geração de hipóteses, desenvolvimento e validação de instrumentos, possibilidade de um contexto para availação, desenvolvimento das intervenções de enfermagem, desenvolvimento de novas perguntas de pesquisa e aplicação da análise do resultado qualitativo. Conclusão. A pesquisa qualitativa resulta em importanes contribuições para a qualidade da prática baseada em evidências.

DESCRITORES: pesquisa qualitativa, prática baseada em evidências, pesquisa em enfermagem

\section{CONTRIBUCIONES DE LA INVESTIGACIÓN CUALITATIVA PARA LA} PRACTICA DE ENFERMERÍA BASADA EN EVIDENCIAS

Objetivo. Este artículo tiene como objetivo identificar las contribuciones de la investigación cualitativa para la práctica de la enfermería basada en evidencias. La investigación cualitativa fue estimulada especialmente a partir de los años 20 y 30 del siglo 20, cuando antropólogos y sociólogos empezaron a usar métodos cualitativos para estudiar el fenómeno humano en ambientes naturales y a partir de un punto de vista holístico. Con el tiempo, otras ciencias, como la enfermería, adoptaron métodos cualitativos para responder a sus preguntas de investigación. La reestructuración de la atención a la salud en la última década trajo consigo mayor confiabilidad atribuida a la investigación en enfermería. La práctica basada en evidencias ha contribuido con ese proceso. El método utilizado fue la investigación en el banco de datos Cumulative Index to Nursing and Allied Health Literature entre 1999 y el presente. La investigación mostró 61 citaciones de la práctica basada en evidencias relacionada con la investigación en Enfermería. Sin embargo, solamente 5 estaban centradas en la práctica basada en evidencias y la investigación cualitativa Los resultados de la investigación mostraron seis contribuciones de la investigación cualitativa para la práctica basada en evidencias: generación de hipótesis, desarrollo y validación de instrumentos, posibilidad de un contexto para evaluación, desarrollo de las intervenciones de enfermería, desarrollo de nuevas preguntas de investigación y aplicación del análisis del resultado cualitativo. La investigación cualitativa da importantes contribuciones para la calidad de la práctica basada en evidencias.

DESCRIPTORES: investigación cualitativa, práctica basada en evidencias, investigación en enfermería

\footnotetext{
${ }^{1} \mathrm{RN}, \mathrm{PhD}$, College of Nursing and Health Science, George Mason University, e-mail: railinge@gmu.edu
} 
The aim of this article is to identify the contributions of qualitative research to evidence-based practice. To place this aim within a broader context, a brief history of qualitative research and of nursing research related to evidence-based practice are presented.

Qualitative research dates back to the 1920 s and 1930s when anthropologists and sociologists made inquiries into human groups. As part of their inquiries, social science researchers developed various research methods to study human phenomena, usually in a naturalistic setting and from a holistic viewpoint. Later, other disciplines, including nursing, political science and education, adopted qualitative methods to answer their research questions ${ }^{(1)}$. Qualitative research also has received renewed attention in health care research. Recently ${ }^{(2)}$, has focused attention on qualitative methods to answer health services research and policy questions ${ }^{(3)}$. In nursing ${ }^{(4)}$, there are examples ${ }^{(4)}$ of evidence based on four patterns of knowing in nursing ${ }^{(5)}$. They view 'scientific data' as associated with empirical knowing; 'standards of practice, codes of ethics, [and] philosophies of nursing' as associated with ethical knowing; 'autobiographical stories' as associated with personal knowing; and 'aesthetic criticism and works of art' as associated with aesthetic knowing. Fawcett et al..$^{(4)}$. believe that each of the four patterns of knowing can be viewed as a theory and that 'different kinds of nursing theories provide different lenses for critiquing and interpreting the different kinds of evidence essential for theory guided, and evidencebased-holistic nursing practice' [italics added].

Evidence-based practice is a relatively new term that has evolved over the past decade; it has been driven by managed care, cost pressures, consumer awareness and information dissemination. But what is evidence-based practice? Three definitions of it follow to highlight differing perspectives. Evidence-based practice is defined in medicine as 'the integration of best research evidence with clinical expertise and patient values ${ }^{\prime(6)}$. Another author ${ }^{(7)}$ defines evidence-based practice in nursing as the conscientious, explicit, and judicious use of theory-derived, research-based information in making decisions about care delivery to individuals or groups of patients and in consideration of individual needs and preferences'. Finally ${ }^{(8)}$, note that 'evidenced-based practice builds on the nursing literature of research utilization by adding other forms of evidence that can be used in making clinical decisions'. What else does the literature contain about qualitative research and evidence-based practice?
METHOD

In a search of the database Cumulative Index to Nursing and Allied Health Literature for the past three years (1999-2002), there were 61 citations for evidence-based practice in the nursing literature. However, when the search was confined to evidence-based practice and qualitative research, only five articles appeared. In the first article ${ }^{(9)}$, described a model for guiding nurses through a process for examining both quantitative and qualitative research. The authors then described one of the steps in the process of using evidence-based practice as synthesizing the best evidence available. To accomplish this step, they used a modification of the Agency for Healthcare Research and Quality guideline, which is considered the gold standard. Rosswurm \& Larrabee ${ }^{(9)}$ synthesized the quantitative studies' evidence and combined it with qualitative reports and clinical judgment. In the second article ${ }^{(10)}$, described the use of qualitative methods in an adjunct study of a randomized trial using evidence-based protocol on incontinence. The qualitative piece revealed that the patients' perceptions of the interpersonal and technical skills of the nurse impacted on the effectiveness of the evidence-based treatment. Data from the 23 respondents indicated that the nurses with good communication skills mitigated the patients' anxiety and embarrassment about incontinence. In the third article ${ }^{(11)}$, conducted a qualitative study of older women with osteoarthritis and noted that a greater understanding of living with osteoarthritis is necessary to improve evidence-based nursing care. In the fourth article ${ }^{(12)}$, reported that qualitative methods played an important role in changing evidence-based practice by illuminating power relationships that permeate practice. The author noted that the agenda for evidence-based practice in nursing will remain theoretical unless practitioners can envision how it will change their clinical practice. In the last article ${ }^{(13)}$, conducted a concept analysis of the meaning of 'context' in healthcare practice as it relates to evidence-based practice or, as they call it, 'research evidence implementation'. The authors frame their analysis of context around three characteristics: strength of organizational culture; strength of leadership; and strength of evaluation. The authors conclude that the meaning of context is not clear: 'thus, the implications of using context as a variable in research studies exploring research implementation are as yet largely unknown'. 
FINDINGS

The findings, which are based on nursing and on personal research, revealed six contributions of qualitative research to evidence-based practice. Each contribution is supported with nursing research examples from over the past five years.

First, a major contribution of qualitative research is that of generating hypotheses. When a qualitative study is being conducted, the findings often suggest hypotheses that can be tested in future research. In a recent study on symptom management of chronic heart failure that included shortness of breath ${ }^{(14)}$, employed a qualitative design to identify numerous self-care strategies used by patients (e.g., resting between physical activities). An example of a hypothesis that could be tested from this study is: patients using resting between physical activities as a self-care strategy show greater decrease in the symptom of shortness of breath than patients who do not use this selfcare strategy. Paterson et al. ${ }^{(15)}$ took the hypothesis testing a step further in their meta-ethnographic synthesis of qualitative studies of the lived experience of people with diabetes. They found that 'balance emerged as the predominant metaphor of the lived experience of diabetes' and that nurses need to value the expertise that patients have gained in living with diabetes.

Second, the development and validation of instruments have long evolved out of the qualitative tradition. The researcher collects qualitative information on a topic and then translates that information into a quantifiable instrument. Sitzia \& Wood ${ }^{(16)}$, for example, reported on the development of an instrument to assess patient satisfaction with chemotherapy treatment. They analyzed quantitative and qualitative data from 173 completed questionnaires to develop the Worthing Chemotherapy Satisfaction Questionnaire. Their qualitative data helped to establish content validity of the instrument. A second example is the development of the Facts on Osteoporosis Quiz, which was based on a review of the qualitative report of the National Institutes of Health consensus conference on osteoporosis ${ }^{(17)}$. Finally ${ }^{(18)}$, reported both quantitative and qualitative data that measured students' perceived writing outcomes. The qualitative data were translated later into a quantitative instrument that measured students' self assessment of their writing skills. The preceding studies demonstrate how qualitative research can be translated into quantifiable instruments that support evidence-based practice. These instruments are then used as outcome measures in studies that assess the implementation of evidence-based practice.

Qualitative research also can be used to validate quantitative instruments. Merkouris et al. ${ }^{(19)}$ developed an instrument to measure patient satisfaction with nursing care. They collected qualitative data from 103 hospital patient interviews and reported that the qualitative data augmented the validity of the Patient Satisfaction Scale and provided important information for upgrading the instrument they had developed. In addition, the percentages of patients who were satisfied were different using quantitative and qualitative measures. The qualitative measure showed less satisfaction than the quantitative measure. Was reported ${ }^{(20)}$ that family concerns in critical care had been examined using the Critical Care Family Needs Inventory but that family members never were asked about their needs during the instrument's development. Burr then conducted a methodological triangulated study to assess the level of agreement between the quantitative instrument and family members' responses to a qualitative interview. The findings indicated that the qualitative data helped to contextualize and clarify the needs of family members.

Third, qualitative research can provide the context for evaluating evidence-based practice in nursing. For example, when evidence-based practice is implemented, an evaluation of the practice is needed. Usually this evaluation is done in anticipation of adopting the practice change. The evaluation should include process as well as outcome. The outcome may be described both quantitatively and qualitatively; however, the process is usually described qualitatively. For example, was ${ }^{(21)}$ investigated pregnant women's experiences of nuchal translucency screening using a qualitative design. She found that women's understanding of the screening varied considerably and suggested that evidence-based midwifery practice needs to examine these routine screenings more critically. In another study, was ${ }^{(22)}$ examined transcriptions from tape recorded qualitative interviews with diabetic patients and providers and used evaluation as one of the categories. They found that patients evaluated how they felt, whereas practitioners evaluated blood glucose concentrations as the control standard in evidence-based practice. Finally, Rosswurm \& Larrabee ${ }^{(9)}$ described their implementation of a protocol for patients with acute confusion in which they included nursing interventions that 
were evidence-based such as enhancing communication.

The outcomes of the interventions were measured by a confusion rating scale, use of restraints, and fall rates in quality improvement data. They or other researchers also could have examined the study's qualitative aspects, such as perceived quality of life by family members and by nursing staff. Such triangulation would provide contextual information that could enrich changes in nursing practice. Authors ${ }^{(23)}$ noted that evidence-based practice is a complex process that requires an 'evaluative culture and commitment by practitioners'.

Fourth, nursing interventions for evidence-based practice can be designed based on qualitative data. For example, Armitage ${ }^{(24)}$, using qualitative data from interviews with eight qualified pediatric nurses, described the development of evidence-based practice related to assessment of respiratory distress in infants. He found that medical diagnoses had more influence on nursing assessment than did nursing diagnoses. The qualitative data provided depth to the previously collected quantitative data. Another dimension is the designing of qualitative studies that will augment interdisciplinary research. For example, recently, a groundbreaking article in the Journal of the American Medical Association was published about breast cancer and women on hormone replacement therapy. Those women who received the estrogen-progestin regimen had a greater chance of breast cancer than those women who received estrogen alone ${ }^{(25)}$. Although the quantitative study was sound, numerous qualitative questions related to this issue need answers. For example, what happens to the women who read the study and then try to make a decision about hormone replacement therapy? What process do they use? What concerns do they have? Will a qualitative study make a difference in evidence-based practice related to hormone replacement therapy? These are questions that qualitative nursing research can help answer.

Fifth, development of new research questions evolves out of qualitative research. Often more questions are raised during the process of and at the end of the research than at the beginning. Therefore, further research that will be the basis for evidence-based practice evolves from qualitative research. Examples ${ }^{(26-27)}$ include developing a quantitative study to answer the question: 'what are the demographic factors that influence adherence to tuberculosis preventive therapy?' from a qualitative study on the tuberculosis explanatory model of Latino immigrants.

Scanlan et al. ${ }^{(28)}$ studied two aspects of classroom teaching: '[how] to understand more fully the meaning and use of reflection in teaching, and how reflection contributes to the development of teaching expertise in the classroom'. The sources of data in this qualitative study were the three investigators (one novice and two more experienced teachers). Over the course of two academic years, the investigators used the following data collection methods: autobiographies; journals reflecting critical teaching incidents; observations of investigators in the classroom; debriefing of observed investigator by the other two investigators and investigator team meetings. The use of content analysis revealed four themes: '(i) making connections, (ii) developmental aspects, (iii) influence of context on reflection, and (iv) influence of emotion on reflection'. The authors concluded that the data collection methods used in this study enhanced their personal reflection in classroom teaching.

Based on the preceding study, some questions for further research include: how does a novice teacher's use of reflection in classroom teaching differ from an expert teacher's use of reflection? How does class size affect both faculty's and student's use of reflection in the classroom? What are contextual factors that contribute to or detract from reflective thinking? What teaching interventions enhance students' use of reflection?

Sixth, the method of Qualitative Outcome Analysis as described $^{(29)}$ is a new addition to the repertoire of how qualitative research can be used in evidence-based practice. This method extends the findings of a qualitative study into clinical application and subsequently evaluates the effects of the application on patients' responses. The preceding authors 'suggest that qualitative evidence is findings, consistent with those of the primary study, produced by another study subsequent to the implementation of strategies'. The difference between this contribution and the fifth contribution is that interventions are developed and evaluated in patient outcomes rather than in more descriptive research.

\section{CONCLUSION}

Based on the previous discussion of qualitative research to evidence-based practice, the conclusion is that 
qualitative research makes important contributions to the quality of evidence-based practice. Because evidencebased practice is a growing phenomenon in nursing, qualitative research, alone or in combination with quantitative research, helps make visible nurses' goals to provide the best health care within an often fiscally constrained environment.

Clinicians, researchers, educators, and administrators can make valuable contributions to qualitative research in evidence-based practice by understanding the importance of it and by implementing it in nursing wherever possible. This goal is important for two reasons. First, evidence-based practice is an important and timely standard in addressing nursing quality. That standard may be diminished if nurses fail to understand the many contributions that qualitative research plays in

\section{REFERENCES}

1. Denzin NK, Lincoln YS. Handbook of qualitative research. Sage: Thousand Oaks; 2000.

2. Agency for Healthcare Research and Quality. Qualitative Methods in Health Services Research. Rockville; 1999.

3. Young A, Taylor SG, McLaughlin-Renpenning $\mathrm{K}$. CONNECTIONS: Nursing Research, Theory, and Practice. Mosby: Saint Louis; 2001.

4. Fawcett J, Watson J, Neuman B, Walker PH, Fitzpatrick JJ. On nursing theories and evidence. J Nurs Scholarsh 2001; 33:115-9.

5. Carper BA. Fundamental patterns of knowing in nursing. Adv Nurs Sci 1978;1(1):13-23.

6. Sackett DL, Straus SE, Richardson WS, Rosenberg W, Haynes RB. Evidence Based Medicine: How to Practice and Teach EBM. London: Churchill Livingstone; 2000.

7. Ingersoll GL. Evidence-based nursing: what it is and what it isn't. Nurs Outlook 2000; 48:151-2.

8. Goode C, Piedalue F. Evidence-based clinical practice. J Nurs Admin 1999; 29(6):15-21.

9. Rosswurm MA, Larrabee JH. A model for change to evidence-based practice. IMAGE: J Nurs Scholarsh 1999; 31:317-22.

10. Kneafsy $R$. The effect of occupational socialization on nurses' patient handling practices. J Clin Nurs 2000; 9(4):58593.

11. Baird CL. Living with hurting and difficulty doing: older women with osteoarthritis. Clin Excell Nurse Pract 2000; 4(4):231-7.

12. Walsh D. Evidence-based care: and finally how do we put all the evidence into practice? Br J Midwifery 2001; 9(2):74-80. 13. McCormack B, Kitson A, Harvey G, Rycroft-Malone J, Titchen A, Seers K. Getting evidence into practice: the meaning of 'context'. J Adv Nurs 2002; 38:94-104.

14. Bennett SJ, Cordes DK, Westmoreland G, Castro R, Donnelly E. Self-care strategies for symptom management in patients with chronic heart failure. Nurs Res 2000; 49:13945.

15. Paterson BL, Thorne S, Dewis M. Adapting to and managing diabetes. IMAGE: J Nurs Scholarsh 1998; 30:5762. evidence-based practice. Second, nurses have and are creating a substantial body of qualitative research in nursing and this trend will continue. However, qualitative research in evidence-based practice will be hampered unless sound and significant qualitative research is conducted by nurses who are committed to it and to its application in nursing practice. When this commitment and application conjoin, evidence-based practice in qualitative nursing research will have reached its full potential.

\section{CKNOWLEDGEMENTS}

The authors wish to thank M. Dear and J. Sorrell for their thoughtful review of the manuscript.

16. Sitzia J, Wood N. Development and evaluation of a questionnaire to assess patient satisfaction with chemotherapy nursing care. Eur J Oncol Nurs 1999; 3(3):12642.

17. Ailinger RL, Harper D, Lasus H. Bone up on osteoporosis: development of the facts on osteoporosis quiz. Orthop Nurs 1998; 17(5):66-73.

18. Silva MC, Cary AH, Thaiss C. When students can't write: solutions through a writing-intensive nursing course. Nurs Health Care Perspect 1999; 20:142-5.

19. Merkouris A, Yfantopoulos J, Lanara V, Lemonidou C. Developing an instrument to measure patient satisfaction with nursing care in Greece. J Nurs Manage 1999; 7(2):91-100.

20. Burr G. Contextualizing critical care family needs through triangulation: an Australian study. Intensive Crit Care Nurs 1999; 14(4):161-9.

21. French S. Women's issues. Perceptions of routine nuchal translucency screening. Br J Midwifery 2000; 8(10):632-8.

22. Hunt LM, Arar NH, Larme AC.Contrasting patient and practitioner perspectives in type 2 diabetes management. West J Nurs Res 1998; 20:656-82.

23. Gerrish K, Clayton J, Nolan M, Parker K, Morgan L. Promoting evidence-based practice: Managing change in the assessment of pressure damage risk. J Nurs Manage 1999; $7(6): 355-62$

24. Armitage G. Nursing assessment and diagnosis of respiratory distress in infants by children's nurses. J Clin Nurs 1999; 8(1):22-30.

25. Schairer C, Lubin J, Troisi R, Sturgeon S, Brinton L, Hoover $R$. Menopausal estrogen and estrogen-progestin replacement therapy and breast cancer risk. J Am Med Assoc 2000; 283(4):485-91.

26. Ailinger RL, Dear MR. Latino immigrants' explanatory models of tuberculosis infection. Qualitative Health Res 1997; 7:521-31.

27. Ailinger RL, Dear MR. Adherence to tuberculosis preventive therapy among Latino immigrants. Public Health Nurs 1998; 15(1):19-24

28. Scanlan JM, Care WD,Udod S. Unravelling the unknowns of reflection in classroom teaching. J Adv Nurs 2002; 38:13643.

29. Morse JM, Penrod J, Hupcey JE. Qualitative outcome analysis: evaluating nursing interventions for complex clinical phenomena. J Nurs Scholarsh 2000; 32:125-30. 